\title{
Determination of Physicochemical Properties and Pharmacokinetic Profiles of Soybean Extracts
}

\author{
Hyun-Chan Jung', Sung-Kyun You ${ }^{1,2}$, SunKyu Kwon ${ }^{3}$, Ji-Sook Hwang ${ }^{1}$ and Cheong-Weon Cho ${ }^{1 \dagger}$ \\ ${ }^{1}$ College of Pharmacy, Chungnam National University, 220 Gung-dong, Yuseong-gu, Daejeon 305-764, Korea \\ ${ }^{2} R \& D$ Institute, Jeil Pharmaceutical Co., Ltd. 117-1 Keunkog-ri, Baekam-myun, Cheoin-gu, Yongin-si, Kyunggi-do 449-861, Korea \\ ${ }^{3}$ CornproductsKorea, Inc., 234-17, Maam-ri, Bubal-eup, Icheon-si, Gyeonggi-do, 467-863, Korea
}

(Received September 20, $2010 \cdot$ Revised October 18, $2010 \cdot$ Accepted October 19, 2010)

\begin{abstract}
Isoflavones have received much attention because of their health-related and clinical benefits such as estrogenic and anti-oxidative activities as well as triggering of natural killer cell activity. However, there are few publications reporting the pharmacokinetic profiles together with physicochemical properties of main isoflavones. Therefore, the pharmacokinetic parameters of main aglycones, daidzein, glycitein and genistein after oral administration of soybean extracts were investigated and the physicochemical properties of soybean extracts were characterized. It was observed that angle of repose was $46^{\circ}$ and tap density, bulk density and porosity were $10.12,4.3$ and $0.86 \mathrm{~g} / \mathrm{cm}^{3}$ and the mean $\mathrm{AUC}_{\text {last }}$ of daidzein, glycitein and genistein was $11.376 \mu \mathrm{g} \cdot \mathrm{h} / \mathrm{mL}, 3.045 \mu \mathrm{g} \cdot \mathrm{h} / \mathrm{mL}$ and $0.825 \mu \mathrm{g} \cdot \mathrm{h} / \mathrm{mL}$, respectively. Cell viability was $60 \%$ at a concentration of $10 \mathrm{mg} / \mathrm{mL}$. Taken together, it was suggested that isoflavones were contained in the soybean products and had an antioxidant activity and this study would be the basis to control the quality of soybean products and study of the bioequivalence between soybean products in future.
\end{abstract}

Key words - Isoflavones, Soybean extracts, Pharmacokinetic, Physicochemical, Cell viability, Solubility

Soybeans contain three types of isoflavones, as four chemical forms (aglycons, glycosides, acetylglucosides, and malonylglucosides) (Jian, 2009). The major aglycons are daidzein, genistein and glycitein. The major glycosides are genistin, daidzin and glycitin. The acetylglucosides include 6"O-acetyldaiazin, 6"-O-acetylgenistin and 6"-O-acetylglycitin and the malonylglucosides contain 6"-O-malonyldaiazin, 6"-Omalonylgenistin and 6"-O-malonylglycitin (Vacek et al., 2008). Isoflavones have received much attention because of their health-related and clinical benefits such as estrogenic and anti-oxidative activities as well as triggering of natural killer cell activity. Particularly, genistein, one of the major isoflavones in Leguminosae, has received great attention as a phytoestrogen demonstrating pharmacological effects such as prevention of hormone-related cancers and bone loss (Zhang et al., 1999).

Moreover, it is known that the bioavailability of isoflavones from soy-based foods and dietary supplements is a critical component in understanding possible beneficial and adverse effects in animal models and humans (Andrade et al., 2010). There is general agreement that absorption in the rodent and

†Corresponding Author :

Tel : +82-42-821-5934, E-mail : chocw@cnu.ac.kr

DOI : 10.4333/KPS.2010.40.6.347 human gut proceeds by rapid release of aglycones through the action of bacterial and intestinal b-glucosidases following ingestion of isoflavone glucosides present in whole soy foods (Chang and Nair, 1995; Day et al., 2000; Hawksworth et al., 1971; Hosoda et al., 2008; Sfakianos et al., 1997). Therefore, many manufactures are controlling the final quantity and profile of isoflavones in soybean product by changing soy cultivar (Eldridge and Kwolek, 1983; Seguin et al., 2004), environmental conditions such as temperature, irrigation and atmospheric $\mathrm{CO}_{2}$ (Eldridge and Kwolek, 1983; Kim et al., 2005; Rasolohery et al., 2008), processing (Aguiar et al., 2009; Genovese et al., 2007; Wang et al., 1998; Yin et al., 2005) and storage (Huang and Chou, 2009; Lee et al., 2003).

After oral administration of genistein with various doses (4, $2,40 \mathrm{mg} / \mathrm{kg}$ ) in rats, the bioavailability of genistein was 38.58 , 24.34 and $30.75 \%$, respectively. The $\mathrm{T}_{\max }, \mathrm{C}_{\max }$ and $\mathrm{AUC}_{0 \rightarrow \infty}$ of genistein after oral administration of genistein $(40 \mathrm{mg} / \mathrm{kg})$, were $2 \mathrm{~h}, 4876.19 \mathrm{ng} / \mathrm{mL}$ and 31,269.66 $\mathrm{ng} \cdot \mathrm{h} / \mathrm{mL}$, respectively (Kwon et al., 2007). Also, there is a publication that the bioavailability of genistein and daidzein in a mouse model by comparing plasma pharmacokinetics of their aglycones and conjugated forms following administration of identical doses $(1.2 \mathrm{mg} / \mathrm{kg}$ genistein and $0.55 \mathrm{mg} / \mathrm{kg}$ daidzein) by either an intravenous injection or gavage of the aglycones in $90 \%$ aqueous solution vs a bolus administration of equimolar doses 
delivered in a food pellet prepared using commercial soy protein isolate (Andrade et al., 2010). However, there are few publications reporting the pharmacokinetic profiles of main isoflavones, simultaneously. Therefore, pharmacokinetic parameters of main aglycones, daidzein, glycitein and genistein were studied after oral administration of soybean extracts, the physicochemical properties of soybean extracts were characterized and then in vitro and in vivo correlations were identified in this study.

\section{Materials and Methods}

\section{Materials}

The standard product of daidzin (040-27741, Wako, Japan), glycitin (077-04691, Wako, Japan), genistin (070-04681, Wako, Japan), daidzein (308-05871, Wako, Japan), glycitein from soybean (070-04701, Wako, Japan) and genistein (446$72-0$, Across, USA) was used in this experiment. Soybean extracts $(6.724 \%$ of daidzin, $2.020 \%$ of glycitin, $1.385 \%$ of genistin, $0.097 \%$ of daidzein, $0.038 \%$ of glycitein, $0.013 \%$ of genistein) were supplied from Corn Products Korea Co. (Ichon, Korea). All other chemicals were reagent grade and used without further purification.

\section{Cell cultures}

Caco-2 cells were purchased from the Korean cell line bank (Seoul, Korea). Caco-2 cells (passage number 46-52) were cultured in DMEM (Dulbecco's Modified Eagle medium) supplemented with $10 \%$ FBS, $1 \%$ NEAA, 100 units $/ \mathrm{mL}$ penicillin and $0.1 \mathrm{mg} / \mathrm{mL}$ streptomycin in a $5 \% \mathrm{CO}_{2}$ atmosphere with $95 \%$ humidity in a $37^{\circ} \mathrm{C}$ incubator.

\section{HPLC condition of standard solutions of isoflavones}

The mixed solution of standard solutions of isoflavones was prepared and diluted 2, 4, 10 and 100 times at a different concentration. After a result, standard solution consisted of 1.96 $\sim 196 \mu \mathrm{g} / \mathrm{mL}$ of daidzin and glycitin, $0.784 \sim 78.4 \mu \mathrm{g} / \mathrm{mL}$ of genistin, $0.098 \sim 9.8 \mu \mathrm{g} / \mathrm{mL}$ of daidzein and glycitein, $0.0245 \sim$ $2.45 \mu \mathrm{g} / \mathrm{mL}$ was obtained and then assayed with HPLC (Shimadzu, Japan). The HPLC system was consisted of a Capcell pak C18 column $(150 \times 4.6 \mathrm{~mm}, 5 \mu \mathrm{m}$; MG120, Shiseido, Tokyo, Japan) thermostated at $30^{\circ} \mathrm{C}$. UV absorption was measured at $254 \mathrm{~nm}$. The mobile phase was consisted of acetonitrile: distilled water: acetic acid (15:85:0.1, v/v \%) (A) and acetonitrile: distilled water: acetic acid (35:65:0.1, v/v \%) (B), respectively. The flow rate was $1 \mathrm{~mL} / \mathrm{min}$ and the elution gradient was as follows: $0 \mathrm{~min}, \mathrm{~A}$ of $100 \% ; 30 \mathrm{~min}$, A of $0 \%$; $35 \mathrm{~min}$, A of $50 \%$.

\section{Solubility measurements}

An excess amount of soybean extracts was added to microcentrifuge tubes containing $1 \mathrm{~mL}$ of distilled water, PBS (phosphate buffered solution, $\mathrm{pH}$ 7.4) and methanol. The samples were put on an end-to-end labquake rotator (Barnstead Thermolyne, Sparks, NV, USA) at $30 \mathrm{rpm}$ at ambient temperature for $72 \mathrm{~h}$ in order to achieve equilibrium. The samples were filtered with a $0.45 \mu \mathrm{m}$ membrane filter (PALL corpotation, Ann Arbor. USA) and then assayed with HPLC.

\section{Determination of physicochemical properties of soybean extracts}

The morphology and surface characteristics of isoflavones were examined by scanning electron microscopy (SEM) (JEOL JSM7500, Thermo, Tokyo, Japan). The samples were mounted onto metal stubs using double-sided adhesive tape onto which the samples were applied. The stubs were sputtercoated with gold particles in a sputter coater for $2 \mathrm{~min}$. On the other hand, the particle size and zeta potential analysis of isoflavones was performed by laser scattering analyzer (ELS8000, Otasuka Electronics, Osaka, Japan). The extracts were dispersed in water, added to the sample dispersion unit and then sonificated in order to minimize the inter-particle interactions. The obscuration range was maintained between $20 \sim 50 \%$. The instrument was set to measure the sample 50 times and the average volume mean diameter was obtained. The physical properties of $100 \mathrm{~g}$ of isoflavones such as apparent density, tap density and flowability were measured using BT-1000 (Dandong bettersize instruments Co.) according to the manufacturer's protocol. Briefly, apparent density was determined by the density of powders falling into the container naturally and tap density was measured by the density of powders after compact the powders in the container by vibration. Compaction ratio was calculated using tap density and apparent density.

\section{Cytotoxicity assay}

After 72 hours incubation of cells ( $70 \%$ confluent) with isoflavones, the cytotoxicity was determined by MTT assay according to the manufacturer's protocol (Sigma-Aldrich; St. Louis, MO, USA). Briefly, after incubation, MTT (3-(4,5-dimethylthiazol-2yl)-2,5-diphenyl-2H-tetrazolium bromide, Sigma) was added to each well and incubated for $2 \mathrm{~h}$ at $37^{\circ} \mathrm{C}$. The crystals of viable cells were solubilized in isopropranolol. The absorbance was determined at $570 \mathrm{~nm}$ in a Microplate Reader (Sunrise, Tecan, Austria). Cell viability (\%) was represented with the (OD of samples-treated cells divided by OD of cells incubated without samples) $\times 100$. 


\section{Animal experiments and drug administration}

All animal experimental protocols were approved by the Animal Care Committee of Chungnam National University. Male Sprague-Dawley rats weighing 240-260 g were purchased from the Dae Han Laboratory Animal Research Co. (Sunganam, Gyeonggido, Korea). The rats were given commercial rat chow diet (No. 322-7-1) purchased from the Superfeed Co. (Gunsan, Jeollabukdo, Korea) and tap water $a d$ libitum. The animals were housed three per cage in laminar flow cages that were maintained at $22 \pm 2^{\circ} \mathrm{C}$, and $50-60 \%$ relative humidity. The animals were kept in these facilities for at least one week prior to the experiment and were fasted for at least $24 \mathrm{~h}$ before commencing of the experiment. The amount of oral administration of isoflavone into rats was $400 \mathrm{mg} / \mathrm{kg}$. After soybean extracts were dissolved into distilled water, corresponding amount was feed using oral zonde $(0.9 \times$ $80 \mathrm{~mm}$, Dongseo, Seoul, Korea). Blood samples $(0.6 \mathrm{~mL})$ were collected at $0,0.25,0.5,1,2,4,6,8$ and 12 hour after the administration. The blood samples were centrifuged at $3,000 \mathrm{~g}$ for $10 \mathrm{~min}$, and the plasma samples were stored at $70^{\circ} \mathrm{C}$ until analyzed by HPLC. The plasma sample $(500 \mu \mathrm{L})$ was placed into a $15 \mathrm{~mL}$ centrifuge tube and then $50 \mu \mathrm{L}$ of 0.2 $\mathrm{M}$ of zinc sulfate solution and $200 \mu \mathrm{L}$ of acetonitrile were added. After vortexing for $15 \mathrm{~min}$, the mixture was centrifuged at $15000 \mathrm{~g}$ for $15 \mathrm{~min}$. The organic phase was transferred to other tubes and evaporated to dryness using a vacuum system. The residues were dissolved in $200 \mu \mathrm{L}$ of methanol and $10 \mu \mathrm{L}$ aliquots were injected into the HPLC system for analysis.

\section{Pharmacokinetic analysis}

Noncompartmental pharmacokinetic analysis was carried out using the $\mathrm{BE}$ computer program, which calculates the AUC (Area under the curve) of the plasma concentration $\left(C_{\mathrm{p}}\right)$ as a function of time $(\mathrm{t})$. The maximum plasma concentration $\left(C_{\max }\right)$ and the time to reach the maximum plasma concentration $\left(T_{\max }\right)$ were obtained from the experimental data. The area under the plasma concentration curve as a function of time $\left(\mathrm{AUC}_{0-t}\right)$ from time zero to the time of the last measured concentration $\left(C_{\text {last }}\right)$ was calculated using the linear trapezoidal rule. The AUC zero to infinite $\left(\mathrm{AUC}_{0 \rightarrow \infty}\right)$ was obtained by adding the $\mathrm{AUC}_{0-t}$, and the extrapolated area was determined by $C_{\text {last }} / K_{\text {el }}$. The total plasma clearance (CL/F) was calculated by dividing the dose by the AUC.

\section{Statistical Analysis}

The Student's $t$ test was used to compare groups. A $p$ value $<0.05$ was considered significant.

\section{Results and Discussion}

\section{Solubility measurements}

When soybean extracts were dissolved into various solvents, daidzin showed the solubility of $1131.29 \pm 45.37 \mu \mathrm{g} / \mathrm{mL}$ in distilled water, $1153.13 \pm 20.43 \mu \mathrm{g} / \mathrm{mL}$ in PBS and $1493.28 \pm$ $326.21 \mu \mathrm{g} / \mathrm{mL}$, respectively. Also, genistin showed the solubility of $576.22 \pm 74.37 \mu \mathrm{g} / \mathrm{mL}$ in distilled water, $618.93 \pm$ $3.75 \mu \mathrm{g} / \mathrm{mL}$ in PBS and $536.21 \pm 212.17$ in methanol. Whileas glycitin exhibited the solubility of $539.01 \pm 113.54 \mu \mathrm{g} / \mathrm{mL}$ in distilled water, $482.47 \pm 48.47 \mu \mathrm{g} / \mathrm{mL}$ in PBS and $1059.34 \pm$ $59.90 \mu \mathrm{g} / \mathrm{mL}$ in methanol. As above, the solubility of daidzin and genistin according to solvents was indifferent but glycitin showed a high solubility in methanol (Figure 1). As well as aglycones, daidzein, glycitein and genistein showed the high solubility in distilled water. These results suggested that the solubility had a good relationship with the content of isoflavones in soybean extracts and glycosides such as daidzin, glycitin and genistin did not convert into aglycones such as daidzein, glycitein and genistein in vitro.

\section{Physicochemical and biopharmaceutical characterizations}

The morphology of soybean extracts was round at a particle size of $1398 \mathrm{~nm}$ and the zeta potential value was $-0.13 \mathrm{mV}$. It was observed that angle of repose was $46^{\circ}$ and tap density, bulk density and porosity were $10.12,4.3$ and $0.86 \mathrm{~g} / \mathrm{cm}^{3}$, respectively through the determination of the physical property of soybean extracts. Therefore, it was suggested that soybean extracts could be easily filled into capsule and compressed into tablet (Ertani et al., 1997). On the other hand, cytotoxicity against Caco-2 cells was carried out because soybean extracts were administered orally. It was found that cell viability was $60 \%$ at a concentration of $10 \mathrm{mg} / \mathrm{mL}$ (Figure 2) and suggested

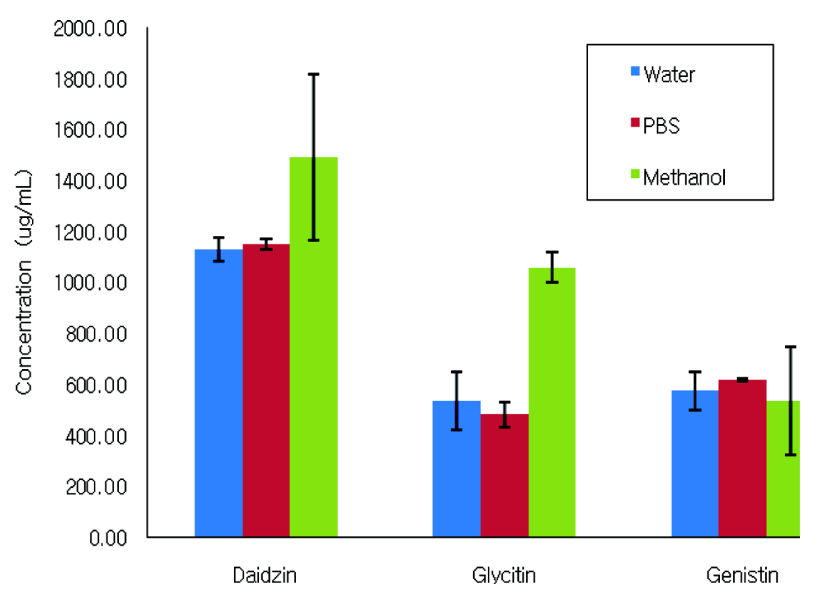

Figure 1. Solubility of main isoflavones in various solvents such as distilled water, PBS and methanol. 


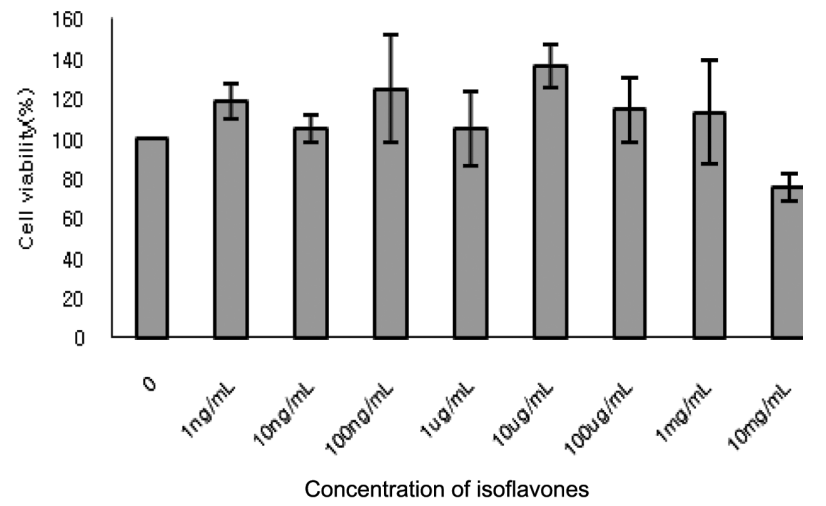

Figure 2. Effects of soybean extracts on Caco-2 cell viability. After overnight incubation of cells ( $70 \%$ confluent) with various concentrations of soybean extracts, the cytotoxicity was determined by MTT assay. The cell viability (\%) was represented with the (OD of soybean extracts-treated cells divided by OD of cells incubated without soybean extracts) $\times 100$.

this soybean extracts would be non cytotoxic as a habitual diet and nutrients (Jian, 2009).

\section{Pharmacokinetic analysis}

After oral administration of soybean extracts $(400 \mathrm{mg} / \mathrm{kg})$, the plasma concentration of daidzein, glycitein and genistein was determined and daidzin, glycitin and genistin were not detected from rat plasma (Figure 3). It was proposed that daidzin, glycitin and genistin which are glycosides of daidzein, gylycitein and genistein were attacked by bacterial and intestinal b-glucosidases when ingested into experimental animals. Aglycones such as daidzein, glycitein and genistein were detected with the retention time of 18.50, 19.80 and $26.40 \mathrm{~min}$, respectively, based on the chromatogram and the calibration curve was linear over the concentration range, 0.0098 0.98 $\mu \mathrm{g}$ /
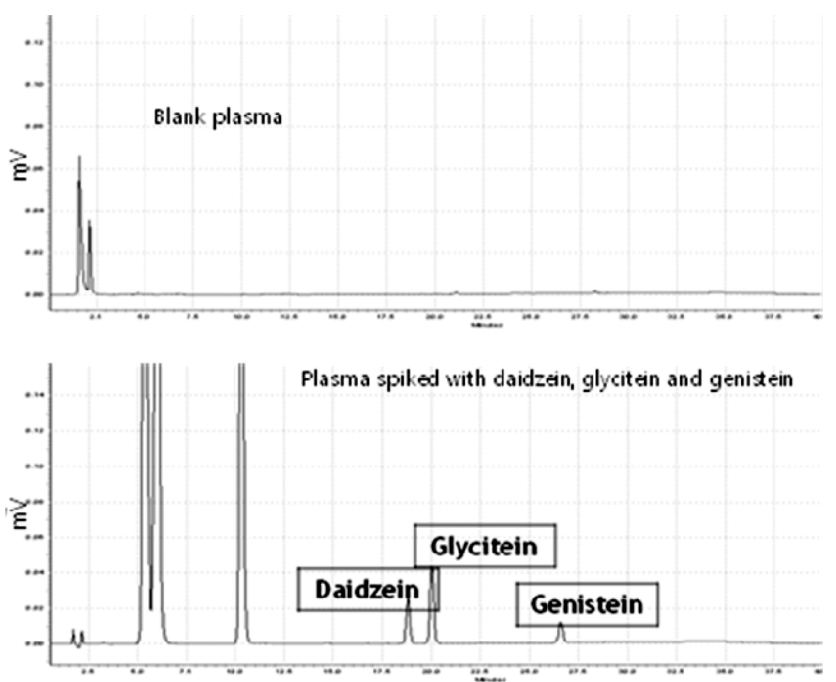

Figure 3. HPLC chromatogram including blank plasma.
$\mathrm{mL}$ of daidzein and glycitein spiked into plasma and $0.0245 \sim$ $0.235 \mu \mathrm{g} / \mathrm{mL}$ of genistein spiked into plasma. The corresponding regression curve was $y=38844 x+8109.5\left(r^{2}=0.9789\right)$ of daidzein, $y=9867 x+1620.5\left(r^{2}=0.9867\right)$ of glycitein and $y=35242 x+$ $159.41\left(r^{2}=0.9884\right)$ of genistein. The mean peak plasma concentration of daidzein, glycitein and genistein was $2.048 \mu \mathrm{g} /$ $\mathrm{mL}, 0.556 \mu \mathrm{g} / \mathrm{mL}$ and $0.147 \mu \mathrm{g} / \mathrm{mL}$, respectively (Figure 4). Also, the mean $\mathrm{AUC}_{\text {last }}$ of daidzein, glycitein and genistein was $11.376 \mu \mathrm{g} \cdot \mathrm{h} / \mathrm{mL}, 3.045 \mu \mathrm{g} \cdot \mathrm{h} / \mathrm{mL}$ and $0.825 \mu \mathrm{g} \cdot \mathrm{h} / \mathrm{mL}$, respectively (Table I). It was known that isoflavones were contained in the soybean products and had an antioxidant activity. It is known that the bioavailability of isoflavones from soy-based foods and dietary supplements is a critical component in understanding possible beneficial and adverse effects in animal models and humans (Andrade et al., 2010).

Compared with other publications (Kwon et al., 2007), the $\mathrm{T}_{\max }, \mathrm{C}_{\max }$ and $\mathrm{AUC}_{0 \rightarrow \infty}$ of genistein were $0.5 \pm 0.1 \mathrm{~h}, 1124.49 \pm$ $236.40 \mathrm{ng} / \mathrm{mL}, 3923.03 \pm 1531.09 \mathrm{ng} \cdot \mathrm{h} / \mathrm{mL}$ after oral administration of genistein with $4 \mathrm{mg} / \mathrm{kg}$ in rats, meanwhile, our results showed those of genistein were $2.75 \pm 3.3 \mathrm{~h}, 147 \pm 20$ $\mathrm{ng} / \mathrm{mL}, 825 \pm 170 \mathrm{ng} \cdot \mathrm{h} / \mathrm{mL}$ after oral administration of soybean extracts according to genistein amount of $0.40 \pm 0.03 \mathrm{mg}$ /

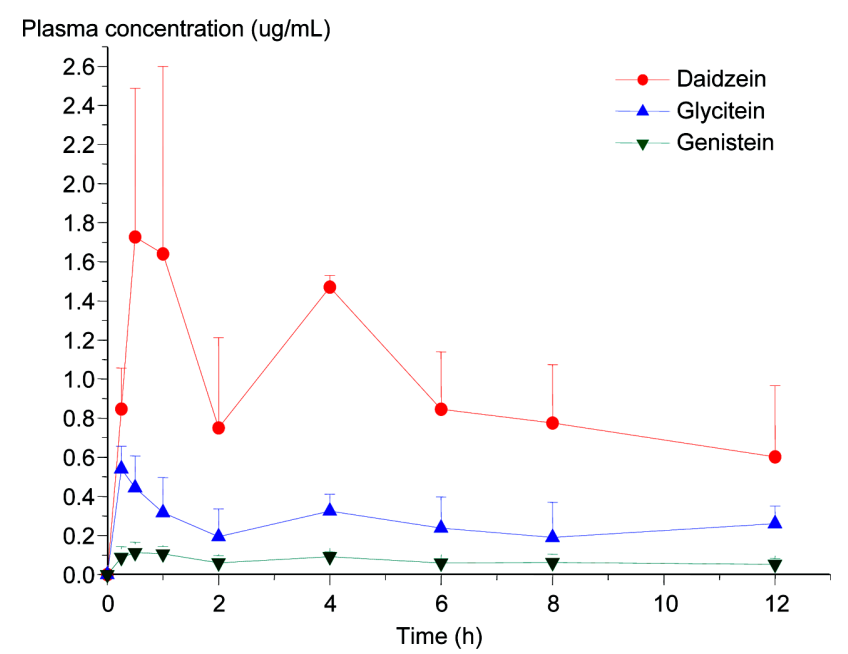

Figure 4. Plasma concentration-time profiles of total plasma isoflavones following oral administration of soybean extracts such as daidzein, glycitein and genistein in SD rats. Each value represents the mean \pm S.D. $(n=5)$.

Table I. Summary of Pharmacokinetic Parameters of Soybean Extracts Following Oral Administration in SD Rats

\begin{tabular}{lccc}
\hline \hline & Daidzein & Glycitein & Genistein \\
\hline AUC $_{\text {last }}(\mu \mathrm{g} \cdot \mathrm{h} / \mathrm{mL})$ & $11.376 \pm 2.496$ & $3.045 \pm 1.209$ & $0.825 \pm 0.171$ \\
$\mathrm{C}_{\max }(\mu \mathrm{g} / \mathrm{mL})$ & $2.048 \pm 0.686$ & $0.556 \pm 0.115$ & $0.147 \pm 0.020$ \\
$\mathrm{~T}_{\max }(\mathrm{h})$ & $1.300 \pm 1.525$ & $1.050 \pm 1.653$ & $2.750 \pm 3.298$ \\
\hline
\end{tabular}


$\mathrm{kg}$ in rats, respectively. Because the administered amount and type of genistein were not the same, the direct comparison was difficult. Taken together, aglycones such as daidzein, glycitein and genistein showed the high solubility in distilled water and their oral absorption into rat had a good relationship with the content of soybean extracts. Also, it was supposed that this study would be the basis to study of the bioequivalence between soybean products.

\section{Conclusions}

Pharmacokinetic parameters of main aglycones, daidzein, glycitein and genistein were studied after oral administration of soybean extracts and the physicochemical properties of soybean extracts were characterized. Soybean extracts having good physical property could be easily filled into capsule and compressed into tablet. In future, it was suggested that this study would be the basis to study of the bioequivalence between soybean products.

\section{Acknowledgements}

This work was supported by the Korea Research Foundation Grant funded by the Korean Government (MOEHRD, Basic Research Promotion Fund) (KRF-2007-331-E00319). Also, we thank SeoYoung Choi for proofreading this manuscript.

\section{References}

Aguiar, C.L., Baptista, A.S., Walder, J.M., Tsai, S.M., CarraoPanizzi, M.C., Kitajima, E.W., 2009. Changes in isoflavone profiles of soybean treated with gamma irradiation. Int. J. Food Sci. Nutr. 60, 387-394.

Andrade, J.E., Twaddle, N.C., Helferich, W.G., Doerge, D.R., 2010. Absolute bioavailability of isoflavones from soy protein isolate-containing food in female balb/c mice. J. Agric. Food Chem. 58, 4529-4536.

Chang, Y.C., Nair, M.G., 1995. Metabolism of daidzein and genistein by intestinal bacteria. J. Nat. Prod. 58, 1892-1896.

Day, A.J., Canada, F.J., Diaz, J.C., Kroon, P.A., McLauchlan, R., Faulds, C.B., Plumb, G.W., Morgan, M.R., Williamson, G., 2000. Dietary flavonoid and isoflavone glycosides are hydrolysed by the lactase site of lactase phlorizin hydrolase. FEBS Lett. 468, 166-170.

Eldridge, A.C., Kwolek, W.F., 1983. Soybean isoflavones: Effect of environment and variety on composition. J Agric. Food Chem. 31, 394-396.

Ertan, G., Ozer, O., Baloğlu E., Güneri, T., 1997. Sustained-release microcapsules of nitrofurantoin and amoxicillin; preparation, in-vitro release rate, kinetic and micromeritic studies. J. Microencapsul. 14, 379-388.
Genovese, M.I., Barbosa, A.C., Pinto Mda, S., Lajolo, F.M., 2007. Commercial soy protein ingredients as isoflavone sources for functional foods. Plant Foods Hum. Nutr. 62, 53-58.

Hawksworth, G., Drasar, B.S., Hill, M.J., 1971. Intestinal bacteria and the hydrolysis of glycosidic bonds. J. Med. Microbiol. 4, 451-459.

Hosoda, K., Furuta, T., Yokokawa, A., Ogura, K., Hiratsuka, A., Ishii, K., 2008. Plasma profiling of intact isoflavone metabolites by high-performance liquid chromatography and mass spectrometric identification of flavone glycosides daidzin and genistin in human plasma after administration of kinako. Drug Metab. Dispos. 36, 1485-1495.

Huang, R.Y., Chou, C.C., 2009. Stability of isoflavone isomers in steamed balck soybeans and black soybean Koji stored under different conditions. J. Agric. Food Chem, 57, 1927-1932.

Jian, L., 2009. Soy, isoflavones, and prostate cancer. Mol. Nutr. Food Res. 53, 217-226.

Kim, S.H., Jung, W.S., Ahn, J.K., Kim, J.A., Chung, I.M., 2005. Quantitative analysis of the isoflavone content and biological growth of soybean (Glycine max L.) at elevated temperature, $\mathrm{CO}_{2}$ level and $\mathrm{N}$ application. J. Sci. Food Agric. 85, 2557-2566.

Kwon, S.H., Kang, M.J., Huh, J.S., Ha, K.W., Lee, J.R., Lee, S.K., Lee, B.S., Han I.H., Lee, M.S., Lee, M.W., Lee, J.H., Choi, Y.W., 2007. Comparison of oral bioavailability of genistein and genistin in rats. Int. J. Pharm. 337, 148-154.

Lee, S.J., Ahn, J.K., Kim, S.H., Kim, J.T., Han, S.J., Jung, M.Y., Chung, I.M., 2003. Variation in isoflavone of soybean cultivars with location and storage duration. J. Agric. Food Chem. 51, 3382-3389.

Rasolohery, C.A., Berger, M., Lygin, A., Lozovaya, V., Nelson, R.L., Dayde, J., 2008. Effect of temperature and water availability during late maturation of the soybean seed on germ and cotyledon isoflavone content and composition. J. Sci. Food Agric. 88, 218-228.

Seguin, P., Zheng, W., Smith, D.L., Deng, W., 2004. Isoflavone content of soybean cultivars grown in eastern Canada. J. Sci. Food Agric. 84, 1327-1332.

Sfakianos, J., Coward, L., Kirk, M., Barnes, S., 1997. Intestinal uptake and biliary excretion of the isoflavone genistein in rats. J. Nutr. 127, 1260-1268.

Vacek, J., Klejdus, B., Lojková, L., Kubán, V., 2008. Current trends in isolation, separation, determination and identification of isoflavones: A review. J. Sep. Sci. 31, 2054-2067.

Wang, C., Ma, Q., Pagadala, S., Sherrard, M.S., Krishnan, P.G., 1998. Changes of isoflavones during processing of soy protein isolates. J. Am. Oil Chem. Soc. 75, 337-341.

Yin, L.J., Li, L.T., Liu, H., Saito, M., Tatsumi, E., 2005. Effects of fermentation temperature on the content and composition of isoflavones and beta-glucosidase activity in sufu. Biosci. Biotechnol. Biochem. 69, 267-272.

Zhang, Y., Song, T.T., Cunnick, J.E., Murphy, P.A., Hendrich, S., 1999. Daidzein and genistein glucuronides in vitro are weakly estrogenic and activate human natural killer cells at nutritionally relevant concentrations. J. Nutr. 129, 399-405. 